\title{
Rapid ion chromatography of L-ascorbic acid, nitrite, sulfite, oxalate, iodide and thiosulfate by isocratic elution utilizing a postcolumn reaction with cerium(IV) and fluorescence detection
}

\author{
Yasuyuki Miura $^{\mathrm{a}, *}$, Masahide Hatakeyama ${ }^{\mathrm{a}}$, Thikara Hosino ${ }^{\mathrm{a}}$, Paul R. Haddad ${ }^{\mathrm{b}}$ \\ ${ }^{a}$ Department of Chemistry, Faculty of Science, Tokai University, Hiratsuka, Kanagawa 259-1292, Japan \\ ${ }^{\mathrm{b}}$ Australian Centre for Research on Separation Science, School of Chemistry, University of Tasmania, GPO Box 252-75,
}

Hobart 7001, Tasmania, Australia

\begin{abstract}
Rapid separation and determination of mixtures of L-ascorbic acid, nitrite, sulfite, oxalate, iodide and thiosulfate by conventional ion chromatography is often difficult due to incomplete separation of L-ascorbic acid and nitrite from the water peak when using eluents giving short elution times for iodide and thiosulfate. Separation of the six species within about 15 min has been achieved by isocratic elution using a resin-based ion-exchange column with a carbonate eluent containing a trace amount of 1,3,5-benzenetricarboxylic acid (BTA) and fluorescence measurement of cerium(III) formed via postcolumn reactions of the separated sample species with cerium(IV). Calibration plots of peak height versus concentration were linear up to $10.0 \mu M(1.76 \mathrm{ppm})$ for L-ascorbic acid, $8.0 \mu M(0.37 \mathrm{ppm})$ for nitrite, $8.0 \mu M(0.70 \mathrm{ppm})$ for oxalate, $80.0 \mu M(10.2$ $\mathrm{ppm})$ for iodide and $25.0 \mu M(2.80 \mathrm{ppm})$ for thiosulfate, whilst the sulfite calibration was linear up to $25.0 \mu M(2.00 \mathrm{ppm})$ when peak area was plotted against concentration. Detection limits (defined as $S / N=3$ ) were 18 ppb for L-ascorbic acid, 4 ppb for nitrite, $16 \mathrm{ppb}$ for sulfite, $7 \mathrm{ppb}$ for oxalate, $72 \mathrm{ppb}$ for iodide and $37 \mathrm{ppb}$ for thiosulfate. The proposed method was applied successfully to the determination of L-ascorbic acid, nitrite, sulfite, oxalate, iodide or thiosulfate in water samples. (C) 2002 Elsevier Science B.V. All rights reserved.
\end{abstract}

Keywords: Detection, LC; Water analysis; Derivatization, LC; Ascorbic acid; Nitrite; Sulfite; Oxalate; Iodide; Thiosulfate; Inorganic anions; Organic acids; Cerium; Benzenetricarboxylic acid

\section{Introduction}

Ion chromatography (IC) is one of the most powerful techniques for the determination of lowmolecular-mass ionic substances. However, one difficulty in using conventional IC arises when poorly

*Corresponding author.

E-mail address: yamiura@keyaki.cc.u-tokai.ac.jp (Y. Miura). retained ions are mixed with more strongly retained species. For example, weakly retained species such as L-ascorbic acid and nitrite are difficult to separate from the water dip when a strong eluent is used in order to resolve strongly retained species such as iodide and thiosulfate in a reasonable time. Several IC approaches have been reported for such mixtures, especially gradient elution has been employed by Sunden et al. [1], Tarter [2] and Wataya et al. [3] for mixtures of fluoride, chloride, nitrite, sulfide, iodide 
and thiosulfate. The present authors have previously established rapid and sensitive separations of mixtures containing sulfide, sulfite and thiosulfate [4], L-ascorbic acid, sulfide, sulfite and thiosulfate [5] and sulfide, sulfite, thiocyanate and thiosulfate [6], based on their postcolumn reactions with iodine and photometric measurement of the residual iodine. In these methods, L-ascorbic acid and sulfide were eluted at retention times very similar to water by using a strong eluent, but these analytes could be detected because the detection system used eliminated the water dip. Therefore, use of such a postcolumn reaction is increasingly desirable from the viewpoint of rapid chromatographic determination of mixtures of weakly and strongly retained species. Wolkoff and Larose have used cerium(IV) as a postcolumn reaction reagent for IC detection of polythionates and thiosulfate [7,8], and Lee and Field have used a similar system for nitrite, nitrate, thiosulfate and iodide, after preliminary reduction of nitrate to nitrite [9]. In the postcolumn reaction, cerium(IV) was reduced to cerium(III) and the cerium(III) was measured fluorometorically. We have found that cerium(IV) can also be converted into cerium(III) by postcolumn reactions with L-ascorbic acid, sulfite and oxalate in an acidic medium. Use of cerium(IV) as a postcolumn agent should therefore provide a rapid, sensitive and selective method for the determination of L-ascorbic acid, nitrite, sulfite, oxalate, iodide and thiosulfate.

In this study, an IC is proposed for rapid determination of L-ascorbic acid, nitrite, sulfite, oxalate, iodide and thiosulfate, based on isocratic elution from an ion-exchange column using a carbonate eluent containing a trace amount of 1,3,5-benzenetricarboxylic acid (BTA), followed by the fluorescence measurement of cerium(III) formed by postcolumn reaction with cerium(IV). The optimal conditions are established by varying the concentration of BTA in the carbonate eluent, the amounts of cerium(IV) and sulfuric acid in the postcolumn reaction solution, the flow-rate of the reaction solution, the reaction temperature and the length of the reaction tube. Under the proposed conditions, the six sample species are determined within 15 min without use of gradient elution. This method is then applied successfully to the analysis of water samples.

\section{Experimental}

\subsection{Reagents}

All of the chemicals used were of analyticalreagent grade and were used without further purification. The water used was distilled twice and then deionized with a Milli-QII instrument (Nippon Millipore, Yonezawa, Yamagata, Japan). An eluent comprising $1.8 \mathrm{~m} M$ sodium carbonate-1.7 $\mathrm{m} M$ sodium hydrogencarbonate $-4 \mu M$ BTA was obtained by adding $4 \mathrm{ml}$ of $1 \mathrm{~m} M$ BTA to a mixture of $3.6 \mathrm{ml}$ of $0.5 \mathrm{M}$ sodium carbonate and $3.4 \mathrm{ml}$ of $0.5 \mathrm{M}$ sodium hydrogen carbonate, and diluting it to 11 with water. A solution of $0.01 M$ cerium(IV) sulfate in $2 M$ sulfuric acid solution was prepared by dissolving $1.03 \mathrm{~g}$ of cerium(IV) sulfate tetrahydrate (Kanto Chemical, Tokyo, Japan) (98\%) in water containing $28.2 \mathrm{ml}$ of sulfuric acid (95\%), and diluting the solution to $250 \mathrm{ml}$ with water. A postcolumn reaction solution of $0.4 \mathrm{~m} M$ cerium(IV) in $0.15 M$ sulfuric acid was prepared by adding $10 \mathrm{ml}$ of the $0.01 M$ cerium(IV) solution to a $250-\mathrm{ml}$ volumetric flask containing $3.5 \mathrm{ml}$ of $5 \mathrm{M}$ sulfuric acid, and diluting it to the mark. A standard nitrite solution $(0.01 M)$ was prepared by dissolving $0.3503 \mathrm{~g}$ of dried sodium nitrite (Wako Pure Chemical, Osaka, Japan) (98.5\%) in water containing $50 \mathrm{ml}$ of $0.125 \mathrm{M}$ sodium hydroxide as a stabilizer $[10,11]$ and diluting to $500 \mathrm{ml}$ with water. A standard solution of oxalate $(0.05 \mathrm{M})$ was obtained by dissolving $3.3668 \mathrm{~g}$ of sodium oxalate (Wako Pure Chemical) $(99.5 \%$ ) in water, and diluting it to $500 \mathrm{ml}$. A standard iodide solution $(0.1 \mathrm{M})$ was prepared by dissolving 4.1709 $\mathrm{g}$ of potassium iodide (Nakalai Tesque, Kyoto, Japan) $(99.5 \%)$ in water containing $100 \mathrm{mg}$ sodium carbonate as a stabilizer, and diluting it to $250 \mathrm{ml}$. Solutions of L-ascorbic acid (about $0.05 \mathrm{M}$ ) and sulfite $(0.05 M)$ were obtained by dissolving $0.89 \mathrm{~g}$ of L-ascorbic acid (Wako Pure Chemical) and $0.52 \mathrm{~g}$ of sodium hydrogen sulfite (Wako Pure Chemical), respectively, in $100 \mathrm{ml}$ of oxygen-free water. A stock thiosulfate solution (about $0.1 \mathrm{M}$ ) was prepared by dissolving sodium thiosulfate pentahydrate (Nakalai Tesque) in water containing a small amount of sodium carbonate $(0.01 \%)$ as a stabilizer. These solutions of L-ascorbic acid, sulfite and thiosulfate 
were then standardized by iodometric titration. Working solutions of L-ascorbic acid, nitrite, sulfite, oxalate, iodide and thiosulfate were obtained by appropriate dilution of their standard solutions.

\subsection{Apparatus}

A model LC-10A pump (Shimadzu, Kyoto, Japan) was used to pass the eluent through a sample injection valve (Rheodyne, Berkeley, CA, USA) equipped with a 300- $\mu$ l loop, and then through a Dionex Ion Pac AG4A guard column $(5 \mathrm{~cm} \times 4 \mathrm{~mm}$ I.D.) and AS4A analytical column $(25 \mathrm{~cm} \times 4 \mathrm{~mm}$ I.D.) connected in series. An additional pump (Model DMX-2000, SNK, Tokyo, Japan) was used to run the postcolumn reaction solution through a mixing tee to mix with the column effluent. Cerium(III) formed by the postcolumn reaction between each analyte and cerium(IV) in the reaction tube was measured with a fluorometer (Model RF-10AXL, Shimadzu). Chromatograms were obtained using a Shimadzu Model U-135 recorder or a Shimadzu Model CR6A Chromatopack.

\subsection{Recommended procedure}

The columns were equilibrated by a $1.8 \mathrm{~m} M$ sodium carbonate- $1.7 \mathrm{~m} M$ sodium hydrogencarbonate eluent containing $4 \mu M$ TBA at a flow-rate of 1.0 $\mathrm{ml} \min ^{-1}$, and then a 300- $\mu \mathrm{l}$ aliquot of sample solution was injected. The postcolumn reaction solution containing $0.4 \mathrm{~m} M$ cerium(IV)-0.15 $M$ sulfuric acid was added to the column effluent at a flow-rate $0.3 \mathrm{ml} \mathrm{min}^{-1}$, and the reaction mixture passed to a reaction tube $(2 \mathrm{~m} \times 0.5 \mathrm{~mm}$ I.D. $)$, in which the sample species reduced the cerium(IV) to produce cerium(III). Fluorescence of the cerium(III) was monitored using excitation and emission wavelengths of 256 and $354 \mathrm{~nm}$, respectively.

\section{Results and discussion}

\subsection{Effect of BTA in carbonate eluent on resolution using conductivity detection}

Initial studies were performed using conductivity detection. When a $1.8 \mathrm{~m} M$ sodium carbonate-1.7 $\mathrm{m} M$ sodium hydrogen carbonate solution at a flowrate of $1.0 \mathrm{ml} \mathrm{min}{ }^{-1}$ was used as the eluent for resolution of common anions on a Dionex Ion Pac AG4A and AS4A columns in series, very long retention times for elution of iodide $(34.6 \mathrm{~min})$ and thiosulfate $(51.4 \mathrm{~min})$ and excessively broad peaks were observed. Whilst an increase in eluent concentration could accelerate the elution of iodide and thiosulfate, it led to incomplete separation of Lascorbic acid from the water peak. Trace amounts of BTA were therefore added to the carbonate-hydrogencarbonate eluent in view of the high eluotropic strength of the BTA solution [12]. The effects of adding BTA are shown in Table 1, from which it can be seen that whilst an increase in BTA concentration accelerated elution of all analytes, retention times of oxalate, iodide and thiosulfate were decreased most significantly. When $4 \mu M$ of BTA was added to the $1.8 \mathrm{~m} M$ carbonate and $1.7 \mathrm{~m} M$ hydrogencarbonate eluent, all six analytes could be resolved completely within about $15 \mathrm{~min}$, with good peak shapes. At higher concentration $(6 \mu M)$ of BTA, the L-ascorbic

Table 1

Effect of concentration of BTA in the carbonate eluent ${ }^{\mathrm{a}}$ on retention times of the six analyte species

\begin{tabular}{|c|c|c|c|c|c|c|}
\hline \multirow{2}{*}{$\begin{array}{l}\text { Concentration } \\
\text { of BTA }(\mu M)\end{array}$} & \multicolumn{6}{|c|}{ Elution time (min) } \\
\hline & L-Ascorbic acid & $\mathrm{NO}_{2}^{-}$ & $\mathrm{SO}_{3}^{2-}$ & $\mathrm{C}_{2} \mathrm{O}_{4}^{2-}$ & $\mathrm{I}^{-}$ & $\mathrm{S}_{2} \mathrm{O}_{3}^{2-}$ \\
\hline 0 & 2.7 & 4.2 & 15.0 & 20.4 & 34.6 & 51.4 \\
\hline 1 & 3.0 & 4.1 & 13.0 & 14.7 & 19.7 & 34.3 \\
\hline 4 & 2.0 & 2.6 & 4.4 & 6.0 & 11.4 & 14.9 \\
\hline 6 & 1.9 & 2.0 & 3.4 & 5.0 & 9.0 & 11.8 \\
\hline
\end{tabular}

Water was eluted at $1.8 \mathrm{~min}$.

${ }^{\mathrm{a}}$ The eluent contained $1.8 \mathrm{~m} M$ sodium carbonate and $1.7 \mathrm{~m} M$ sodium hydrogencarbonate was used at flow-rate of $1.0 \mathrm{ml} \mathrm{min}{ }^{-1}$. 
acid peak overlapped partially with the nitrite peak, and also the separation of iodide from thiosulfate became poorer. Consequently, a $1.8 \mathrm{~m} M$ carbonate$1.7 \mathrm{~m} M$ hydrogencarbonate solution containing 4 $\mu M$ BTA was used as an eluent in this work and a chromatogram obtained using this eluent with conductivity detection is shown in Fig. 1. An injection of the six analyte species (together with sulfate which often coexists with sulfite) showed that Lascorbic acid could not be separated completely from the water dip, nor could sulfite be separated from sulfate. In view of this, fluorescence detection after postcolumn reactions was utilized in further experiments.

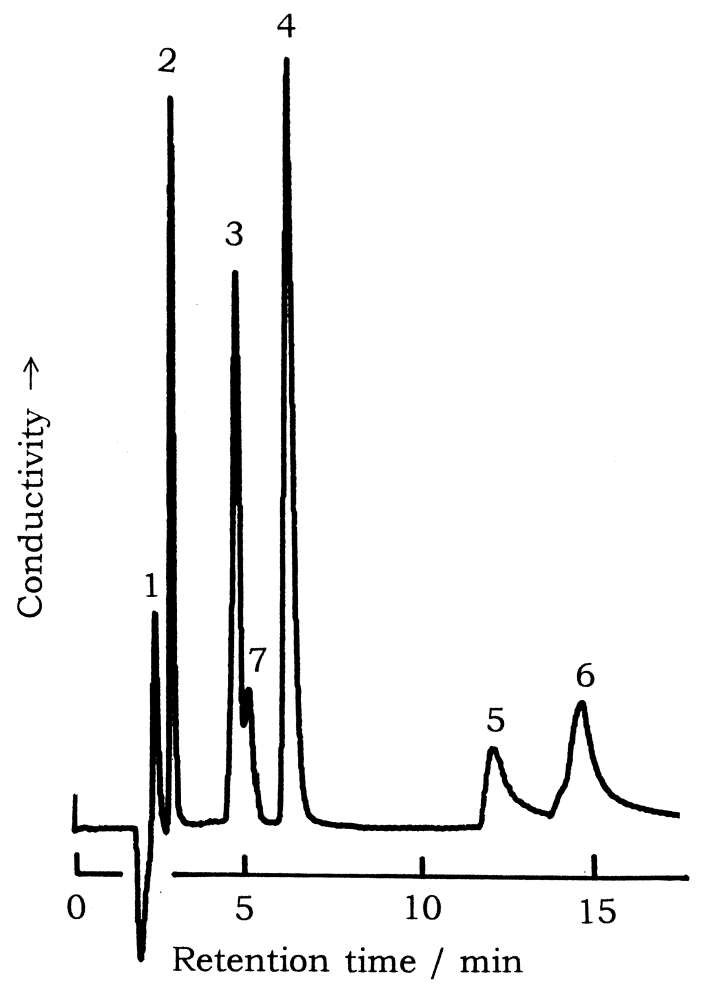

Fig. 1. Chromatograms of the six analyte species and sulfate obtained using suppressed conductivity detection. A $1.8 \mathrm{mM}$ sodium carbonate-1.7 $\mathrm{mM}$ sodium hydrogencarbonate eluent containing $4 \mu M 1,3,5$-benzenetricarboxylate was used at a flowrate of $1.0 \mathrm{ml} \mathrm{min}{ }^{-1}$. Peaks: $1=10 \mu M$ L-ascorbic acid; $2=10$ $\mu M$ nitrite; $3=10 \mu M$ sulfite; $4=10 \mu M$ oxalate; $5=10 \mu M$ iodide; $6=50 \mu M$ thiosulfate; $7=2 \mu M$ sulfate.

\subsection{Selection of wavelengths for fluorescence measurement of cerium(III)}

Excitation and emission spectra of cerium(III) were measured, in which the cerium(III) solution was prepared by adding $10 \mathrm{ml}$ of $0.6 \mathrm{mM}$ cerium(IV) sulfate in $0.15 M$ sulfuric acid and $5 \mathrm{ml}$ of $0.1 \mathrm{~m} M$ L-ascorbic acid to a $25-\mathrm{ml}$ volumetric flask containing $5 \mathrm{ml}$ of a $1.8 \mathrm{~m} M$ sodium carbonate-1.7 $\mathrm{m} M$ sodium hydrogencarbonate- 4 $\mu M$ BTA solution, and diluting it to the mark. Maximum fluorescence intensity of cerium(III) in the solution was obtained at wavelengths of 256 and $354 \mathrm{~nm}$ for excitation and emission, respectively. These wavelengths were used in all subsequent experiments.

\subsection{Optimization of the postcolumn reaction conditions}

First, the composition of the postcolumn reaction solution was optimized. The concentration of cerium(IV) in the reaction solution was varied over the range $0.1-0.8 \mathrm{~m} M$, the concentration of sulfuric acid being held constant at $0.15 \mathrm{M}$. Peak heights for the tested analytes are plotted in Fig. 2a, from which it can be seen that peak heights for all analytes except L-ascorbic acid reached a maximum at 0.4 $\mathrm{m} M$ cerium(IV). Next, the effect of sulfuric acid concentration in the $0.4 \mathrm{~m} M$ cerium(IV) solution was measured over the range $0.1-0.5 \mathrm{M}$; Fig. $2 \mathrm{~b}$ shows that increased acidity caused an slight increase in peak heights for nitrite, oxalate, iodide and thiosulfate, but a decrease for L-ascorbic acid and sulfite. A $0.4 \mathrm{~m} M$ cerium(IV) in $0.15 M$ sulfuric acid was selected as the optimum postcolumn reaction solution. The flow-rate of the reaction solution was varied over the range $0.1-0.5 \mathrm{ml} \mathrm{min}{ }^{-1}$ and the results obtained are shown in Fig. 3. Peak heights generally decreased with increasing the flow-rate, but sulfite, iodide and thiosulfate showed maximal peak heights at a flow-rate of $0.3 \mathrm{ml} \mathrm{min}{ }^{-1}$. Reaction coils comprising tubes $(0.5 \mathrm{~mm} \mathrm{I}$. D.) of three different lengths $(0.5,2.0$ and $5.0 \mathrm{~m})$ was used to find the optimal length of tube for the postcolumn reaction. The effect of tube length on peak height is listed in Table 2. A reaction tube of 2-m length gave slightly lower peak heights for L-ascorbic acid, sulfite and 

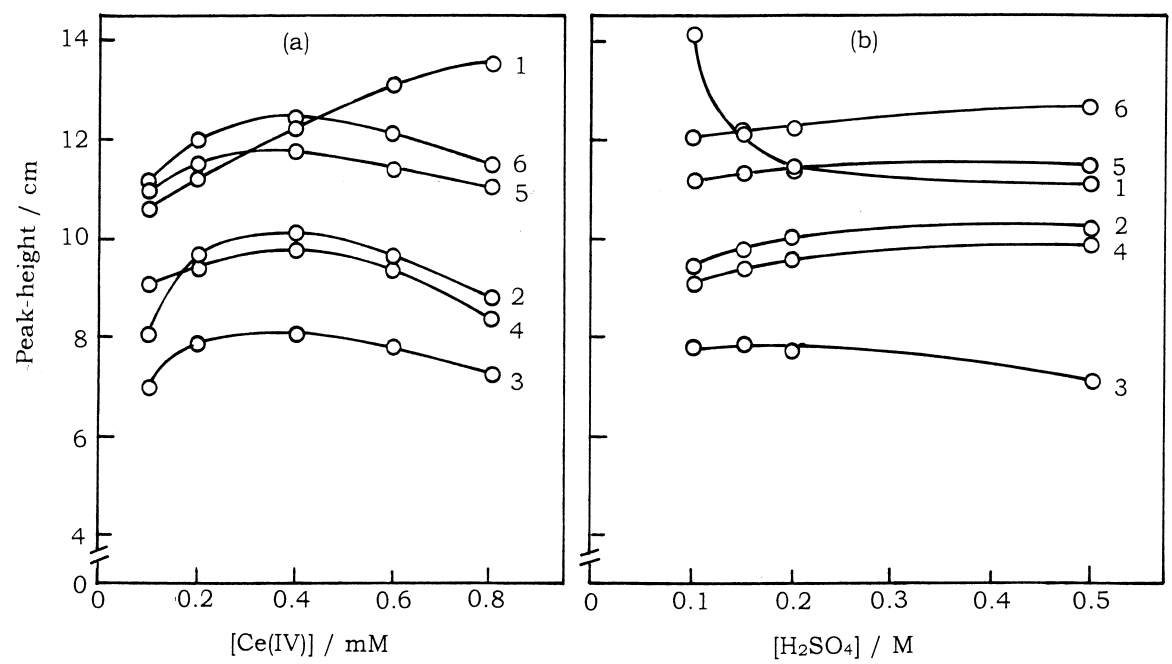

Fig. 2. Effects of concentrations of (a) cerium(IV) and (b) sulfuric acid in the postcolumn reaction solution on peak heights of the analyte species. (a) Effect of concentration of cerium(IV) in $0.15 M$ sulfuric acid; (b) effect of concentration of sulfuric acid in $0.4 \mathrm{~m} M$ cerium(IV) sulfate solution. Key: $1=8 \mu M$ L-ascorbic acid; $2=5 \mu M$ nitrite; $3=20 \mu M$ sulfite; $4=5 \mu M$ oxalate; $5=40 \mu M$ iodide; $6=20 \mu M$ thiosulfate.

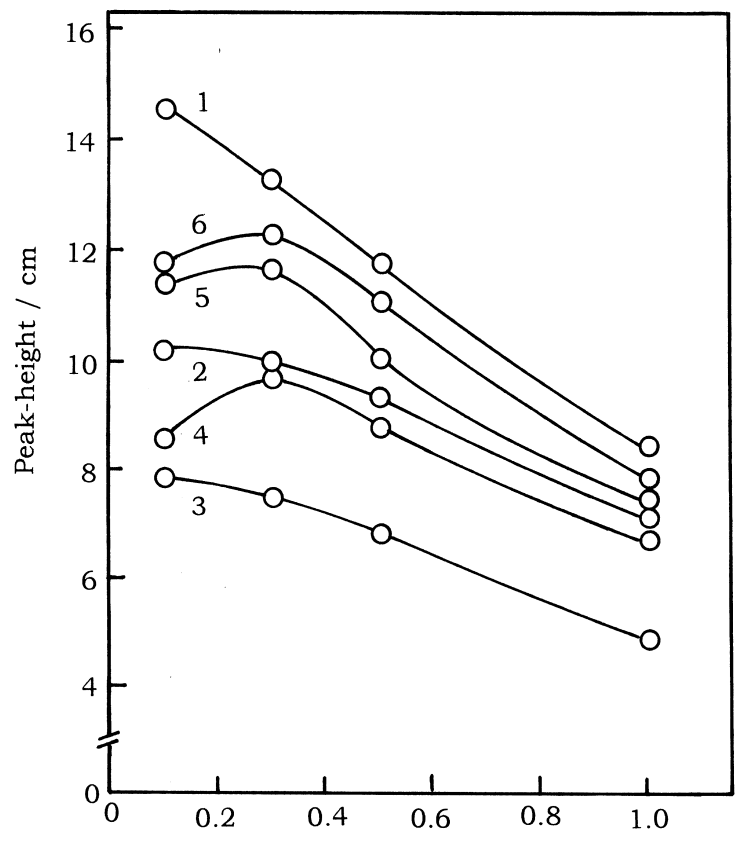

Flow rate of $\mathrm{Ce}(\mathrm{IV})$ solution / $\mathrm{ml} \mathrm{min}^{-1}$

Fig. 3. Effect of flow-rate of the postcolumn reaction solution on peak heights of the analyte species. Key: $1=8 \mu M$ L-ascorbic acid; $2=5 \mu M$ nitrite; $3=20 \mu M$ sulfite; $4=5 \mu M$ oxalate; $5=40$ $\mu M$ iodide; $6=20 \mu M$ thiosulfate. oxalate compared with a $0.5-\mathrm{m}$ tube, but gave almost same peak height for each analyte except nitrite and oxalate as a 5-m tube. A 2-m reaction tube was therefore used in further studies. The effect of temperature (over the range $10-30{ }^{\circ} \mathrm{C}$ ) of the postcolumn reaction on peak height is also listed in Table 2. Peak heights for all analytes except Lascorbic acid showed only a minor increase when the temperature was raised, and for this reason the postcolumn reaction was carried out at room temperature of around of $22{ }^{\circ} \mathrm{C}$.

A chromatogram obtained under the selected optimal conditions is shown in Fig. 4, from which it can be seen that complete resolution was obtained in 15 min with no interference from any water dip.

\subsection{Analytical performance characteristics}

Calibration plots were constructed using 300- $\mu$ 1 aliquots of sample solutions containing L-ascorbic acid, nitrite, sulfite, oxalate, iodide and thiosulfate, separated under the conditions described in Section 2.3. Calibration graphs based on peak height, for all analyte species except sulfite, were linear up to 10 $\mu M(1.76 \mathrm{ppm})$ for L-ascorbic acid, $8 \mu M(0.37 \mathrm{ppm})$ for nitrite, $8 \mu M(0.70 \mathrm{ppm})$ for oxalate, $80 \mu M$ 
Table 2

Effects of reaction coil tubing length and temperature on the postcolumn reaction

\begin{tabular}{|c|c|c|c|c|c|c|}
\hline \multirow[t]{2}{*}{ Parameter } & \multicolumn{6}{|l|}{ Peak height $(\mathrm{cm})$} \\
\hline & $\begin{array}{l}\text { L-Ascorbic acid } \\
(6 \mu M)\end{array}$ & $\begin{array}{l}\mathrm{NO}_{2}^{-} \\
(6 \mu M)\end{array}$ & $\begin{array}{l}\mathrm{SO}_{3}^{2-} \\
\left(25^{\mu} \mu M\right)\end{array}$ & $\begin{array}{l}\mathrm{C}_{2} \mathrm{O}_{4}^{2-} \\
(4 \mu M)\end{array}$ & $\begin{array}{l}\mathrm{I}^{-} \\
(20 \mu M)\end{array}$ & $\begin{array}{l}\mathrm{S}_{2} \mathrm{O}_{3}^{2-} \\
(15 \mu M)\end{array}$ \\
\hline \multicolumn{7}{|c|}{ Tube length $^{\mathrm{a}}$ (m) } \\
\hline 0.5 & 9.6 & 11.5 & 9.7 & 8.0 & 6.0 & 10.2 \\
\hline 2.0 & 8.5 & 11.3 & 8.8 & 7.3 & 6.2 & 10.2 \\
\hline 5.0 & 8.3 & 9.4 & 8.1 & 6.3 & 6.1 & 10.6 \\
\hline \multicolumn{7}{|c|}{ Temperature $^{\mathrm{b}}\left({ }^{\circ} \mathrm{C}\right)$} \\
\hline 10 & 8.0 & 10.9 & 8.4 & 6.9 & 5.9 & 10.0 \\
\hline 22 & 8.5 & 11.3 & 8.8 & 7.3 & 6.2 & 10.2 \\
\hline 30 & 11.4 & 11.9 & 9.4 & 7.3 & 6.0 & 10.4 \\
\hline
\end{tabular}

${ }^{\text {a }}$ Temperature was adjusted to $22{ }^{\circ} \mathrm{C}$.

${ }^{\mathrm{b}}$ A 2-m tube was used.

Table 3

Precision of the proposed method and detection limits

\begin{tabular}{|c|c|c|c|c|}
\hline \multirow[t]{2}{*}{ Species } & \multicolumn{3}{|l|}{ Precision $^{a}$} & \multirow{2}{*}{$\begin{array}{l}\text { Detection limit } \\
\text { at } S / N=3 \\
(\mathrm{ppb})\end{array}$} \\
\hline & $\begin{array}{l}\text { Mean value } \\
(\mathrm{ppm})\end{array}$ & $\begin{array}{l}\text { SD } \\
(\mathrm{ppm})\end{array}$ & $\begin{array}{l}\text { RSD } \\
(\%)\end{array}$ & \\
\hline L-Ascorbic acid & 0.518 & 0.016 & 3.2 & 18 \\
\hline $\mathrm{NO}_{2}^{-}$ & 0.093 & 0.002 & 2.2 & 4 \\
\hline $\mathrm{SO}_{3}^{2-}$ & 1.60 & 0.014 & 0.9 & 16 \\
\hline $\mathrm{C}_{2} \mathrm{O}_{4}^{2-}$ & 0.176 & 0.004 & 2.0 & 7 \\
\hline $\mathrm{I}^{-2^{-4}}$ & 2.57 & 0.046 & 1.9 & 72 \\
\hline $\mathrm{S}_{2} \mathrm{O}_{3}^{2-}$ & 1.12 & 0.032 & 2.9 & 37 \\
\hline
\end{tabular}

\footnotetext{
${ }^{\mathrm{a}}$ The precision was estimated from five replicate results obtained for a mixture containing $0.523 \mathrm{ppm}$ L-ascorbic acid, $0.092 \mathrm{ppm}$ nitrite,
} $1.60 \mathrm{ppm}$ sulfite, $0.176 \mathrm{ppm}$ oxalate, $2.54 \mathrm{ppm}$ iodide and $1.12 \mathrm{ppm}$ thiosulfate; SD, standard deviation; RSD, relative standard deviation.

Table 4

Determinations of L-ascorbic acid in soft drinks and nitrite in river water

\begin{tabular}{|c|c|c|c|c|c|}
\hline \multirow[t]{2}{*}{ Sample } & \multicolumn{4}{|c|}{ Proposed method } & \multirow{2}{*}{$\begin{array}{l}\text { PCR-UV detection } \\
\text { Content in original } \\
\text { sample (ppm) }\end{array}$} \\
\hline & $\begin{array}{l}\text { Added } \\
(\mathrm{ppm})\end{array}$ & $\begin{array}{l}\text { Found }^{\mathrm{b}} \\
(\mathrm{ppm})\end{array}$ & $\begin{array}{l}\text { Recoveries }^{\mathrm{b}} \\
(\%)\end{array}$ & $\begin{array}{l}\text { Content in original } \\
\text { sample (ppm) }\end{array}$ & \\
\hline \multicolumn{6}{|c|}{ L-Ascorbic acid in soft drinks ${ }^{c}$} \\
\hline \multirow[t]{2}{*}{ A } & 0 & 0.678 & - & 271.2 & 275 \\
\hline & 0.793 & 1.477 & 100.7 & 273.6 & - \\
\hline \multirow[t]{2}{*}{ B } & 0 & 0.616 & - & 246.4 & 256 \\
\hline & 0.878 & 1.451 & 100.8 & 249.1 & - \\
\hline \multicolumn{6}{|c|}{ Nitrite in river water ${ }^{\mathrm{d}}$} \\
\hline \multirow[t]{3}{*}{$\mathrm{C}$} & 0 & 0.079 & - & 0.317 & - \\
\hline & 0.046 & 0.127 & 102.5 & 0.324 & - \\
\hline & 0.092 & 0.173 & 102.5 & 0.324 & - \\
\hline
\end{tabular}

\footnotetext{
${ }^{\mathrm{a}}$ Excess iodine after a postcolumn reaction with L-ascorbic acid in the column effluent was measured photometrically [4]; PCR, postcolumn reaction.

${ }^{\mathrm{b}}$ Mean from three replicate results.

${ }^{\mathrm{c}}$ Dilutions to 400 times the original volume with water were used.

${ }^{\mathrm{d}}$ Dilutions to four times the original volume with water were used.
} 
(10.2 ppm) for iodide, and $25 \mu M(2.80 \mathrm{ppm})$ for thiosulfate. When peak area was plotted against concentration the calibration plot for sulfite was linear up to $25.0 \mu M(1.20 \mathrm{ppm})$. In all cases, correlation coefficients of more than 0.999 were obtained. The precision of this method and the detection limits of analyte species are shown in Table 3.

Interference effects by various foreign ions on the determination of the analytes were investigated. Ions such as $\mathrm{Cl}^{-}, \mathrm{Br}^{-}, \mathrm{SO}_{4}^{2-}, \mathrm{HPO}_{4}^{2-}$, formate, propionate, acetate, lactate, $n$-butyrate, citrate, tartrate, malonate, succinate, $\mathrm{NH}_{4}^{+}, \mathrm{Na}^{+}, \mathrm{K}^{+}, \mathrm{Mg}^{2+}, \mathrm{Ca}^{2+}, \mathrm{Zn}^{2+}$, $\mathrm{Co}^{2+}$, and $\mathrm{Al}^{3+}$ gave no chromatographic peaks at concentrations as high as $1 \mathrm{~m} M . \mathrm{NO}_{3}^{-}$at $1 \mathrm{~m} M$ caused a negative peak between nitrite and sulfite peaks, but it did not gave any interference with the determinations of nitrite and sulfite. Each cation of

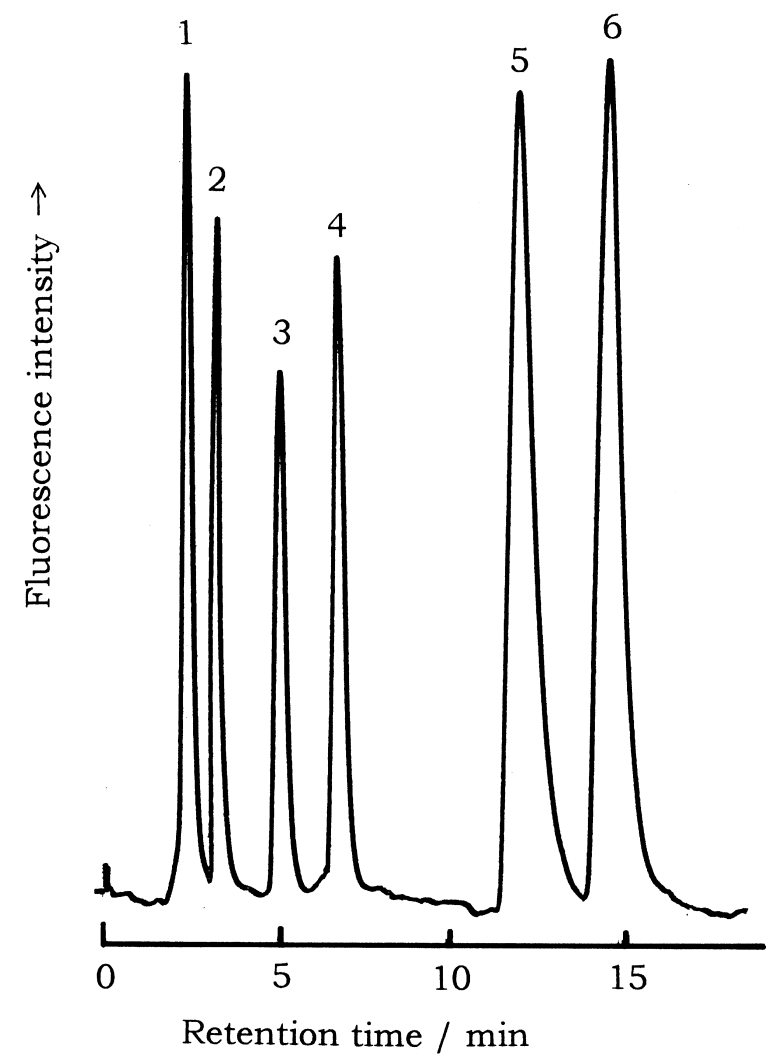

Fig. 4. Chromatograms of L-ascorbic acid, nitrite, sulfite, oxalate, iodide and thiosulfate with postcolumn fluorescence detection. Peaks: $1=8 \mu M$ L-ascorbic acid; $2=5 \mu M$ nitrite; $3=20 \mu M$ sulfite; $4=5 \mu M$ oxalate; $5=40 \mu M$ iodide; $6=20 \mu M$ thiosulfate.
$\mathrm{Cu}^{2+}, \mathrm{Fe}^{2+}$ and $\mathrm{Fe}^{3+}$ gave small negative peaks at elution time close to L-ascorbic acid. But these cations in amounts of $1 \mathrm{~m} M$ could be eliminated with the cation-exchange column $(50 \mathrm{~mm} \times 4.0 \mathrm{~mm}$ I.D.) packed with Amberlite IR-120 resin (30-50 mesh) in the $\mathrm{Na}^{+}$form. Anions of $\mathrm{IO}_{3}^{-}, \mathrm{BrO}_{3}^{-}$and $\mathrm{S}^{2-}$ were eluted at retention times close to $\mathrm{L}$-ascorbic acid, and maleate was eluted at a time close to sulfite, but these foreign ions when present at 0.1 $\mathrm{m} M$ did not interfere with the determination of $\mathrm{L}$ ascorbic acid and sulfite.

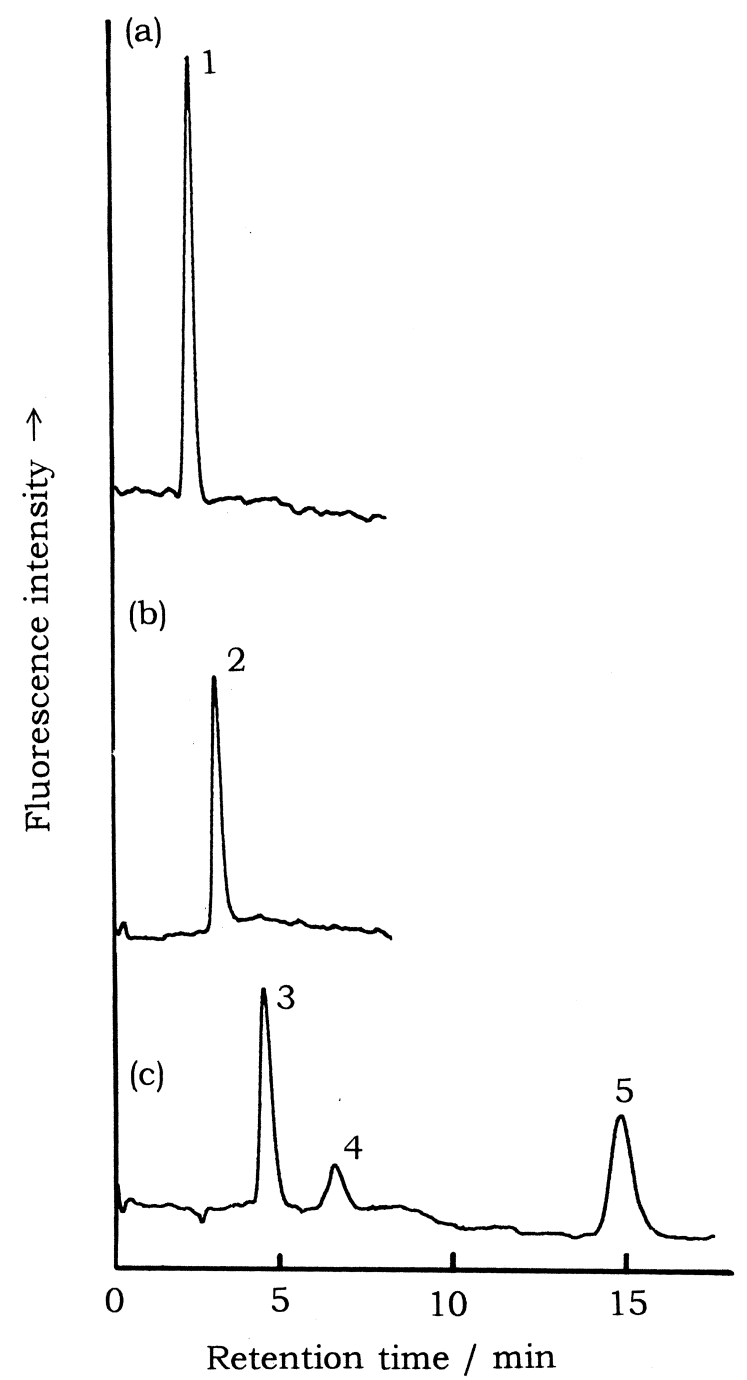

Fig. 5. Chromatograms of analyte species in water samples. (a) L-ascorbic acid in soft drink; (b) nitrite in river water; (c) sulfite, oxalate and thiosulfate in groundwater. Peaks: $1=\mathrm{L}$-ascorbic acid; $2=$ nitrite; $3=$ sulfite $4=$ oxalate $5=$ thiosulfate. 
Table 5

Determination of sulfite, oxalate and thiosulfate in groundwater

\begin{tabular}{|c|c|c|c|c|c|}
\hline \multirow[t]{2}{*}{ Analyte } & \multicolumn{4}{|l|}{ Proposed method } & \multirow{2}{*}{$\begin{array}{l}\text { PCR-UV detection } \\
\text { Content in original } \\
\text { sample }^{\mathrm{c}}(\mathrm{ppm})\end{array}$} \\
\hline & $\begin{array}{l}\text { Content in original } \\
\text { sample (ppm) }\end{array}$ & $\begin{array}{l}\text { Added }^{\mathrm{b}} \\
(\mathrm{ppm})\end{array}$ & $\begin{array}{l}\text { Found }^{\mathrm{b}, \mathrm{c}} \\
(\mathrm{ppm})\end{array}$ & $\begin{array}{l}\text { Recovery }{ }^{\mathrm{b}, \mathrm{c}} \\
(\%)\end{array}$ & \\
\hline $\mathrm{SO}_{3}^{2-}$ & 1.272 & 1.040 & 1.708 & 103.1 & 1.280 \\
\hline $\mathrm{C}_{2} \mathrm{O}_{4}^{2-}$ & 0.058 & 0.106 & 0.136 & 101.0 & - \\
\hline $\mathrm{S}_{2} \mathrm{O}_{3}^{2-}$ & 0.746 & 2.240 & 2.607 & 99.7 & 0.744 \\
\hline
\end{tabular}

${ }^{\mathrm{a}}$ Excess iodine after a postcolumn reactions with L-ascorbic acid in the column effluent was measured photometrically [4]; PCR, postcolumn reaction.

${ }^{\mathrm{b}}$ Samples diluted to 2 times the original volume with water were used.

${ }^{\mathrm{c}}$ Mean from three replicate results.

\subsection{Application to the analysis of water samples}

The proposed method was applied to the determination of the six analyte species in water samples (soft drink, river water and groundwater). Table 4 lists the results for the determination of L-ascorbic acid in soft drinks and for the determination of nitrite in river water, and Table 5 the results for the determination of sulfite, oxalate and thiosulfate in groundwater. Fig. 5 shows chromatograms obtained for these water samples. These results show that the proposed method could be applied successfully to the rapid determination of the six analytes in treated and natural water samples without the need for gradient elution or sample pretreatment.

\section{References}

[1] T. Sunden, M. Lindgren, A. Cedergren, D.D. Siemer, Anal. Chem. 55 (1983) 2.

[2] J.G. Tarter, Anal. Chem. 56 (1984) 1264.

[3] T. Wataya, K. Hayakawa, K. Nomura, M. Miyazaki, Bunseki Kagaku 43 (1994) 817.

[4] Y. Miura, M. Tsubamoto, T. Koh, Anal. Sci. 10 (1994) 545.

[5] Y. Miura, T. Maruyama, T. Koh, Anal. Sci. 11 (1995) 617.

[6] Y. Miura, K. Fukasawa, T. Koh, J. Chromatogr. A 804 (1998) 143.

[7] A.W. Wolkoff, R.H. Larose, Anal. Chem. 47 (1975) 1003.

[8] A.W. Wolkoff, R.H. Larose, J. Chromatogr. Sci. 14 (1978) 353.

[9] S.H. Lee, L.R. Field, Anal. Chem. 56 (1984) 2647.

[10] T. Nomura, G. Nakagawa, Nippon Kagaku Kaishi 1978 (1978) 1380

[11] A.A. Ensafi, M. Samimifar, Talanta 40 (1993) 1375

[12] Y. Miura, J.S. Fritz, J. Chromatogr. 482 (1989) 155. 